\title{
THE QUANTITATIVE ESTIMATION OF TOTAL IRON STORES IN HUMAN BONE MARROW
}

\author{
By EDWARD GALE, JOHN TORRANCE, AND THOMAS BOTHWELL* \\ (From the Department of Medicine, University of Witwatersrand Medical School, \\ Johannesburg, South Africa)
}

(Submitted for publication December 3, 1962; accepted March 7, 1963)

In normal adult males, about $25 \%$ of the body iron content is in storage depots (1). This iron exists in two forms: as a diffuse soluble fraction called ferritin, in which the molecules are dispersed, and as insoluble aggregates of hemosiderin, which can be visualized by conventional microscopy (2). Although the liver is regarded as the chief storage organ, chemical analyses suggest that it normally contains up to $300 \mathrm{mg}$ (3-5), which is only between one-quarter and one-third of what can be mobilized from total stores when healthy young males are repeatedly phlebotomized (6). Although little is known of the quantities present in other organs, hemosiderin can be seen in the reticuloendothelial cells of the bone marrow (7) and spleen (8), and there is some chemical evidence to indicate that significant amounts of storage iron may be present in skeletal muscles $(9,10)$.

The present study was undertaken to find out how much iron is normally stored in the reticuloendothelial cells of the bone marrow and to define the extent to which these stores can expand when iron overload is present. In addition, a comparison was made between the concentrations of iron present in the bone marrows and livers of subjects with varying quantities of storage iron.

\section{MATERIALS AND METHODS}

Clinical material. The total iron stores present in bone marrow were estimated in 61 adult subjects undergoing thoracotomy. Forty-one were white and the remainder were Bantu. The individual diagnoses are shown in Table I.

The chemical concentrations of storage iron were estimated in the livers and bone marrows of adult Bantu and white subjects dying in the hospital. The Bantu

* This work was supported by grant AM04912-02 from the National Institutes of Health and by a grant from the Council for Scientific and Industrial Research, South Africa. specimens (58 males and 44 females) were obtained from Baragwanath Hospital, Johannesburg, and the white specimens (25 males and 28 females) from the General Hospital, Johannesburg.

The use of radioiron as a marrow label. When a tracer quantity of radioiron is injected intravenously, most of it is taken up by the red-cell precursors of the bone marrow (11). This iron is subsequently released over the next few days as part of the hemoglobin of new red cells, and the percentage present in circulation at 10 to 14 days has been used as a measure of the fraction initially taken up by the bone marrow (12). If a specimen of bone marrow is therefore removed between 18 and 24 hours after the injection of the radioiron (i.e., at a time when marrow activity is maximal, and circulating activity is negligible), it is possible to use the $\mathrm{Fe}^{59}$ as a label for relating values in the sample to the total marrow. This principle, which has previously been employed for estimating the total number of cell precursors (13-15), was used in the present study as a means of calculating the total amount of storage iron present in the bone marrow. To do this, we must assume that the reticulum cells containing storage iron are fairly evenly dispersed throughout the erythroid marrow.

Isotopic techniques. Subjects undergoing thoracotomy were given between 5 and $10 \mu \mathrm{c}$ high specific activity $\mathrm{Fe}^{60}$ citrate intravenously between 18 and 24 hours before surgery. A weighed sample of this solution was set aside as a standard. Blood samples were collected over the next few hours, and plasma volumes were then calculated from the line of clearance of radioiron as described previously (16). The total blood volume was obtained from the plasma volume and packed cell volume corrected for the body: venous hematocrit ratio at an altitude of 5,900 feet (17). With this approach, the mean figure for blood volume in the group was $68.2 \mathrm{ml}$ per $\mathrm{kg}$ (SD, 10.7).

The rib removed at operation was squeezed dry, and the marrow so obtained was weighed and counted for radioactivity in a well-type counter. The amount of storage iron present was then measured chemically (see Chemical methods).

Blood samples were collected from all the subjects 10 to 14 days after the injection of radioiron. The total percentage of injected radioactivity in circulation was then calculated by using the estimation of blood volume obtained from radioiron data on the first day of the study. The mean figure for the group was $83 \%$ (SD, 10.7). On 
the assumption that the radioiron present in circulation at this time was in the marrow 18 to 24 hours after the original injection, it was then possible to obtain a measure of the total iron stores present in bone marrow. Marrow iron stores $=\left(\right.$ fraction of injected $\mathrm{Fe}^{59}$ in circulation at 10 to 14 days $\times$ counts injected/counts in sample) $\times$ nonheme iron in marrow sample.

Chemical methods. The quantity of nonheme iron present in specimens of marrow was estimated by a modification of the method of Brückmann and Zondek (18). Four $\mathrm{ml}$ saturated sodium pyrophosphate was added to the marrow and sufficient $20 \%$ trichloroacetic acid to give a final volume of $10 \mathrm{ml}$. (In this calculation the specific gravity of the marrow was assumed to be 1.0). After thorough mixing, the tube was heated in a water bath and was maintained at a temperature of $80^{\circ} \mathrm{C}$ for 10 minutes. During this time the solution was stirred frequently. After cooling, the mixture was filtered and an iron estimation was carried out on a sample of the filtrate by use of the thioglycolic acid method (19).

The validity of the whole procedure as a means of separating heme from nonheme iron was established in preliminary studies with solutions of hemoglobin and ferritin and suspensions of hemosiderin granules. Fer-
TABLE I

Clinical diagnoses in 61 patients subjected to thoracotomy

\begin{tabular}{|c|c|c|c|c|}
\hline \multirow[b]{2}{*}{ Diagnosis } & \multicolumn{2}{|c|}{ White } & \multicolumn{2}{|c|}{ Bantu } \\
\hline & $\mathbf{M}$ & $\mathrm{F}$ & $\mathbf{M}$ & $\mathrm{F}$ \\
\hline Mitral stenosis & 7 & 9 & 0 & 0 \\
\hline Intrathoracic neoplasms & 8 & 0 & 1 & 0 \\
\hline Pulmonary tuberculosis & 3 & 0 & 8 & 3 \\
\hline Pulmonary sepsis & 0 & 4 & 6 & 2 \\
\hline Hiatus hernia & 6 & 4 & 0 & 0 \\
\hline Total & 24 & 17 & 15 & 5 \\
\hline
\end{tabular}

ritin was prepared by the method of Mazur and Shorr (20), and hemosiderin by the method of Shoden and Sturgeon (21). Only 5\% (range, 3 to $8 \%$ ) of heme iron was present in the filtrate. Calculations based on the quantities of hemoglobin present in marrow samples indicated that the error that could be introduced by hemoglobin iron was not more than $10 \mu \mathrm{g}$ per $\mathrm{g}$ marrow. The mean recovery of ferritin iron in concentrations varying between 100 and $2,000 \mu \mathrm{g}$ per $\mathrm{ml}$ was $104 \%$

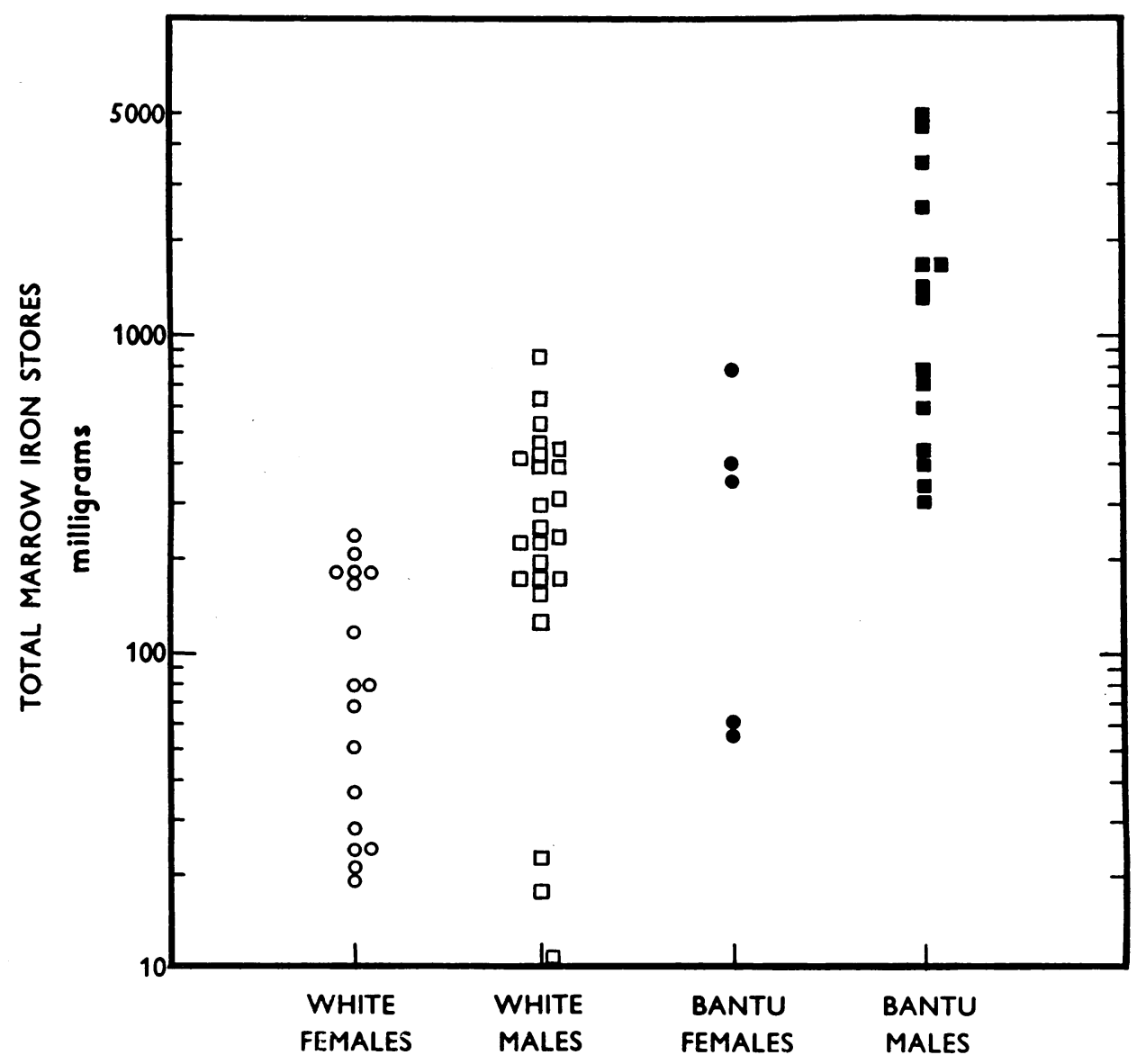

Fig. 1. Calculated values for total marrow iron stores in 61 human subjects. 


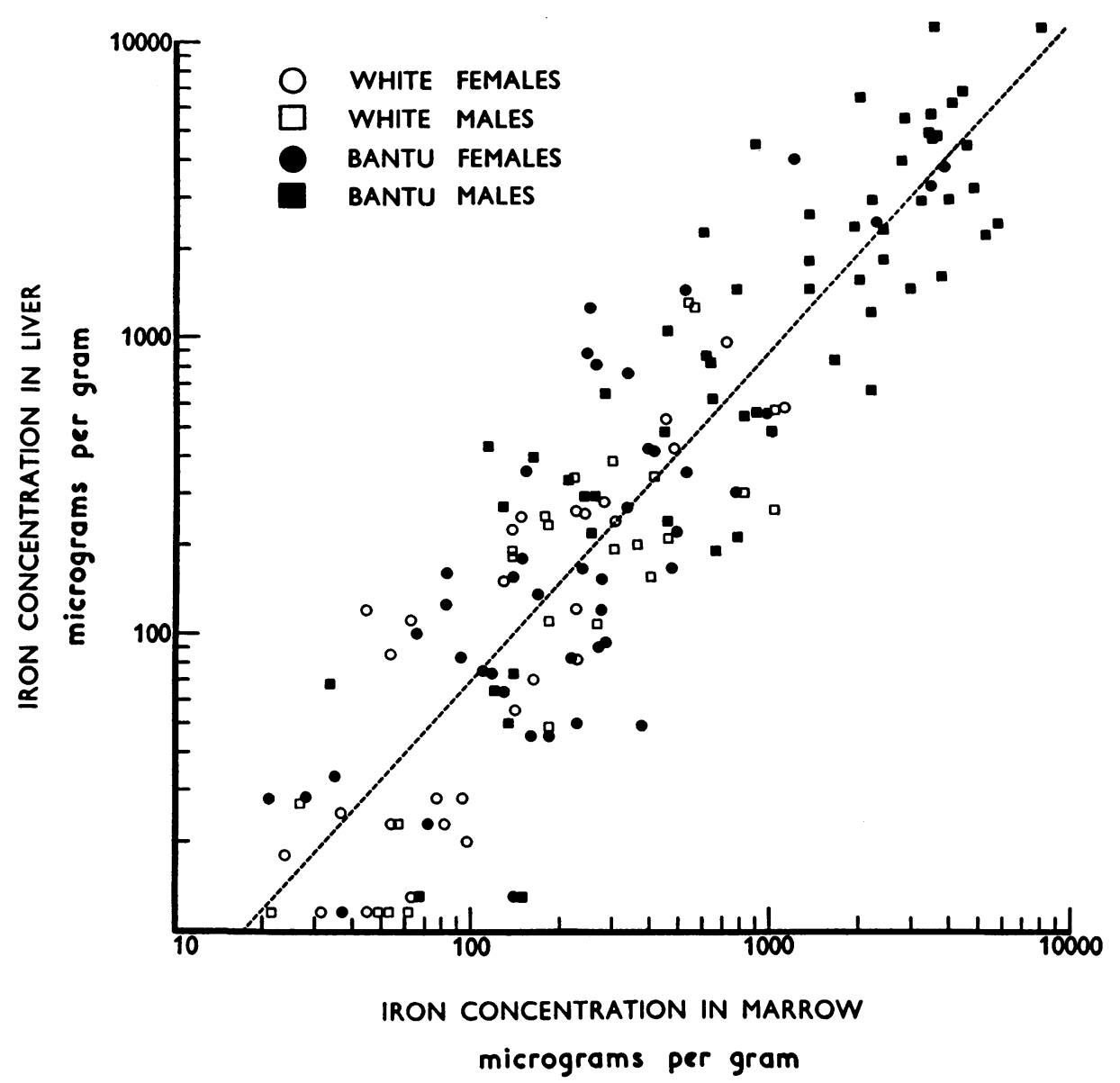

Fig. 2. Correlation BetweEn Storage iron concentrations in the marrows and livers of 155 NECROPSY SUBJECTS. The regression line is indicated $(\mathrm{r}=+0.88, \mathrm{p}<.001)$.

(range 100 to $106 \%$ ), whereas that of hemosiderin iron in concentrations varying between 70 and $10,000 \mu \mathrm{g}$ per $\mathrm{ml}$ was $103 \%$ (range 97 to $111 \%$ ).

In necropsy studies, specimens of rib and samples of liver were collected. Marrow was obtained from the ribs by squeezing them dry, and the concentrations of nonheme iron were estimated with the method described in the previous paragraphs. As the validity of results obtained for the concentrations of storage iron in marrow depended on there being a moderately constant relationship between storage iron and the weight of marrow samples, some preliminary studies were done in which the concentrations of storage iron were estimated in samples of marrow obtained from different sites. Specimens were taken from two sites in subjects with concentrations of marrow storage iron varying between 15 to $4,476 \mu \mathrm{g}$ per $\mathrm{g}$. The average difference from the mean of each pair of observations was $5.9 \%$ (range 0 to $23 \%$ ) in 16 cases. It was felt that this degree of agreement was sufficiently close for meaningful information to be obtained from single samples.

The concentration of total iron present in each formalin-treated sample of liver was estimated as described pre- viously (8). In addition, the concentration of heme iron was estimated on a separate sample of liver, and the concentration of storage iron was then obtained by subtracting this result from the figure for total iron. This proved somewhat difficult as there are no simple, described techniques for the quantitative estimation of hemoglobin iron in formalin-treated tissues. The method eventually devised was as follows. Approximately $1 \mathrm{~g}$ formalin-treated liver was blotted and weighed. The sample was then cut into slices and placed in a $50-\mathrm{ml}$ volumetric flask. One-half $\mathrm{ml}$ of the detergent sodium alkyl sulfate ${ }^{1}$ was added, and the flask was made up to volume with $1 \mathrm{~N}$ sodium hydroxide. The addition of the detergent ensured a clear final filtrate. The flask was placed in an oven at $56^{\circ} \mathrm{C}$ for 18 hours. After cooling, the solution was filtered, and the optical density of the alkali-heme was determined by using an Evelyn colorimeter with a 540 filter. The concentration of hemoglobin iron present was then read from a calibration curve constructed with hemoglobin solutions of known iron con-

1 Marketed as Teepol by the Shell Chemical Co., London, England. 
tent which had been treated in the same way. With this technique, reproducible calibration curves were obtained on solutions of hemoglobin that had been stored in formalin for as long as 3 months.

In an attempt to establish the specificity of the method, estimations of hemoglobin iron were carried out on deeply jaundiced livers obtained from rats in which the bile duct had been tied several days previously. The results were no higher than in normal rats. In addition, the fact that concentrations of heme iron were in the same range as those obtained by other methods on fresh liver specimens $(9,22)$ further supports the validity of the present technique.

Histological methods. In the majority of studies, samples of marrow specimens were squashed onto slides that were then stained for iron by Dry's method (23). The arbitrary histological gradings of storage iron in marrow particles were as follows: grade 0 -no visible iron under oil immersion (magnification $\times 720$ ) ; grade $1+$-small iron particles just visible in reticulum cells under oil immersion (magnification $\times 720$ ) ; grade $2+-$ small, sparsely distributed iron particles usually visible under low power (magnification $\times 80$ ); grade $3+-$ numerous small particles present in reticulum cells throughout the marrow particles; grade 4+-larger particles throughout the marow with tendency to aggregate into clumps; grade $5+$ - dense, large clumps of iron throughout the marrow; and grade $6+$-very large deposits of iron, both intra- and extracellular, which obscure cellular detail in the marrow particles.

\section{RESULTS}

Total iron stores in the marrow (Figure 1). The mean value in 17 white females was $99 \mathrm{mg}$ (range 19 to $237 \mathrm{mg}$ ), and in 24 white males, $288 \mathrm{mg}$ (range 10 to $833 \mathrm{mg}$ ). Only 3 of the males had values below $100 \mathrm{mg}$, and 2 of these subjects gave a history of previous gastrointestinal hemorrhage. The 3 males with figures above 500 mg were all suffering from bronchial carcinoma.

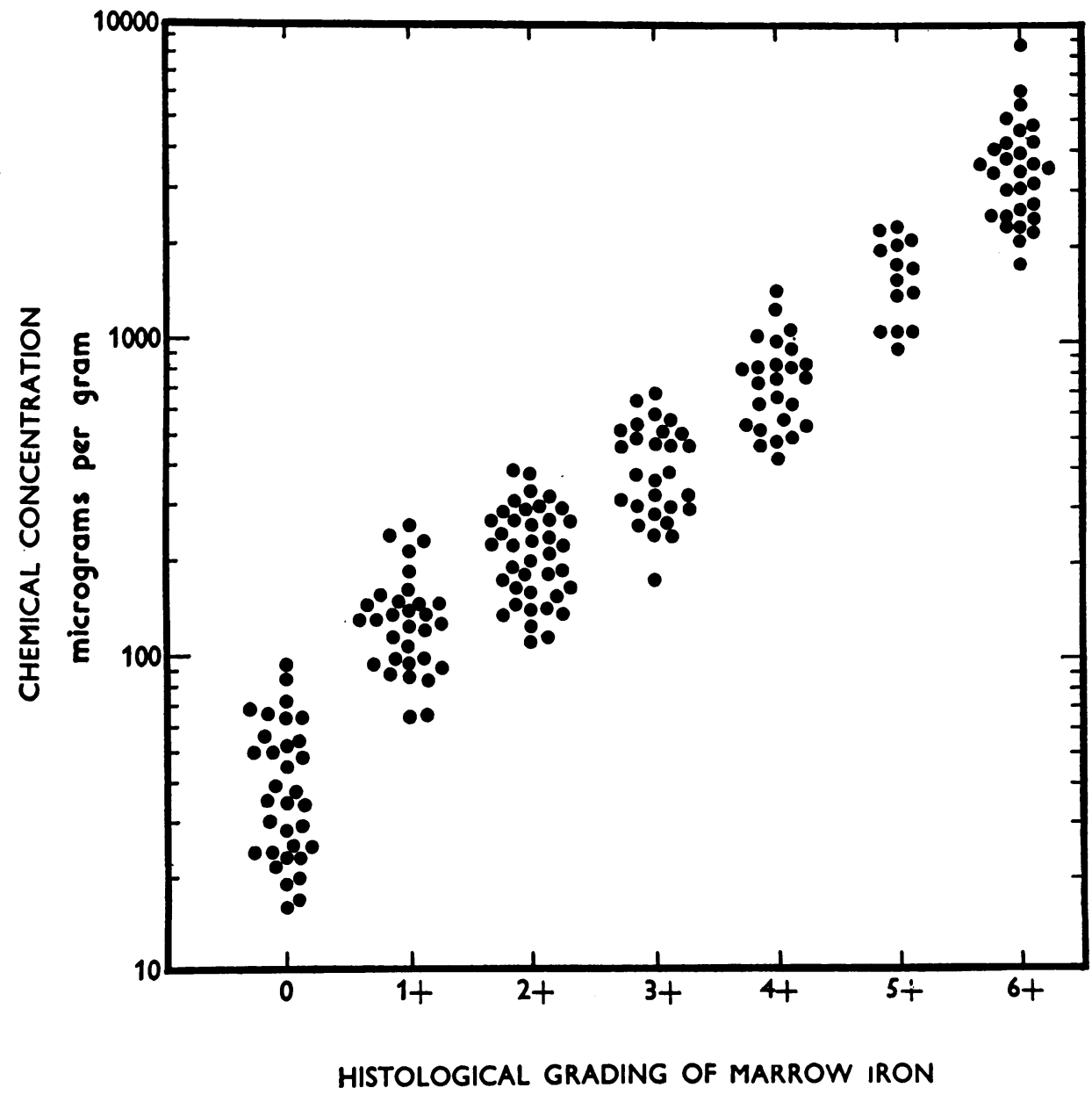

Fig. 3. RANGe OF CHEMiCAL CONCENTRATIONS OF STORAGE IRON IN THE MARROWS OF 199 SUBJECTS IN WHOM THE EXTENT OF RETICULOENDOTHELIAL STORES WAS ASSESSED HISTOLOGICALLY. 
Only 5 Bantu females were studied. Results showed a wide scatter, with values ranging between 56 and $781 \mathrm{mg}$. The mean value in 15 Bantu males was $1,629 \mathrm{mg}$ (range 304 to 4,820 $\mathrm{mg}$ ).

Correlation between concentrations of storage iron in marrow and liver (Figure 2). The results in 155 subjects show that the concentrations of storage iron present in the two organs were approximately the same over a very wide range.

Correlation between chemical and histological assessment of storage iron in the marrow. The results in 199 subjects are shown in Figure 3. Although there was some degree of overlap, moderately good agreement was obtained between the histological gradings and the chemical concentrations of storage iron in the marrow. The mean figures for each grade were as follows : $0=43 \mu \mathrm{g}$ per $g(\mathrm{SD}, 23) ; 1+=130 \mu \mathrm{g}$ per $\mathrm{g}(\mathrm{SD}, 50)$; $2+=223 \mu \mathrm{g}$ per $\mathrm{g}(\mathrm{SD}, 75) ; 3+=406 \mu \mathrm{g}$ per $\mathrm{g}$ $(\mathrm{SD}, 131) ; 4+=762 \mu \mathrm{g}$ per $\mathrm{g}(\mathrm{SD}, 247) ; 5+$ $=1,618 \mu \mathrm{g}$ per $\mathrm{g}(\mathrm{SD}, 464)$; and $6+=3,681 \mu \mathrm{g}$ per $g(\mathrm{SD}, 1,400)$.

\section{DISCUSSION}

Estimates of the amounts of iron present in stores have been made in different ways. When normal subjects are repeatedly phlebotomized, the red-cell deficit is corrected by mobilizing iron from stores. Calculations from such data indicate that the total stores in healthy young males vary between 1,000 and $1,500 \mathrm{mg}$ (6). Although data derived from an isotopic dilution technique have given a mean figure of only $600 \mathrm{mg}$ in man (24), these discrepancies are not surprising, since the response to repeated phlebotomies is a measure of the total mobilizable stores, whereas the isotopic technique is only a measure of miscible stores.

The major sites of storage iron in the body have been demonstrated by using both histological and chemical methods. The liver normally contains up to $300 \mathrm{mg}$, and significant quantities are present in the reticuloendothelial cells of the bone marrow $(7,25)$ and spleen $(3,8)$. In addition, there is some chemical evidence to suggest that significant amounts of storage iron may be present in skeletal muscles $(9,10)$. There is, however, little quantitative information on the total amounts of iron present in organs other than the liver and spleen.

In the present study, an attempt was made to estimate the total amount of storage iron in the bone marrow. This was done by adapting an isotopic dilution technique which has been previously used for gauging the number of cell precursors in bone marrow (13-15). The data obtained with this technique indicate a mean figure for marrow storage iron of $288 \mathrm{mg}$ in white males and $99 \mathrm{mg}$ in white females. Some of the individual values must certainly have been modified by the diseases from which the subjects were suffering. For example, the highest figures in males were obtained in subjects with cancer, while the lowest results were in subjects with hiatus hernia and a history of previous gastrointestinal hemorrhage. In spite of these qualifications, it is felt that the results obtained are probably a fair reflection of the findings in the general population, as the mean values in the 7 males and 9 females suffering from uncomplicated mitral stenosis, with no signs of rheumatic activity, were very similar to those in the whole group, i.e., $256 \mathrm{mg}$ and 70 mg, respectively. All these subjects had hemoglobin levels above $13 \mathrm{~g}$ per $100 \mathrm{ml}$, and only two, both of whom were females, had ever donated blood ( 2 and 5 pints, respectively). The wellmarked sex difference, which is probably a reflection of the increased losses of iron via menstruation and pregnancies in females, has also been noted previously in histological assessments of bone-marrow iron (26) and in chemical estimations of liver iron concentrations $(9,27)$.

Figures for storage iron in Bantu subjects were a good deal higher than in white subjects. The mean figure of $1,629 \mathrm{mg}$ in Bantu males was approximately 6 times the value in the white subjects, and the highest figure obtained was 17 times greater. Although the majority of these subjects were suffering from sepsis, the relative hemosiderosis that is so often a feature in chronic infection would not be expected to raise reticuloendothelial stores to more than about twice normal (28), and the very high values obtained therefore represent an absolute increase in the body iron content. This fits in with several previous studies that have demonstrated a high incidence of varying degrees of iron overload in the adult Bantu population of Southern Africa (8, 22, 
29-31). The excess iron in these subjects is largely derived from the containers used for the preparation of alcoholic beverages (32). In most individuals, the iron is almost exclusively stored in the liver and in the reticuloendothelial system of the body $(8,29)$.

In an extension of the initial investigation, specimens of bone marrow and liver were obtained at necropsy from white and Bantu subjects in order to compare the concentrations of storage iron present in the two organs. It was of considerable interest to find that the concentrations of iron were very similar in subjects with depleted s'ores, normal stores, and all degrees of iron overload. Although it is not possible to translate the necropsy data into accurate figures for the absolute amounts of storage iron present in bone marrow and liver, some idea of the relative capacities of the two organs can be obtained from the isotopic data. Calculations from these results gave a mean figure for the total marrow weight of about 1,200 $\mathrm{g}$, which is in the same range as the normal liver weight. This suggests that the liver and marrow have a capacity to store iron that is of the same order. Although the relationship probably holds true when iron stores are normal or moderately increased, there is usually significant hepatomegaly when gross degrees of iron overload are present $(3,5)$, and the liver's capacity is therefore increased. In quantitative terms, the highest marrow iron concentration obtained in the autopsy study was $8,647 \mu \mathrm{g}$ per $\mathrm{g}$. If it is presumed that the total marrow weight in this subject was 1,200 $\mathrm{g}$, then the total marrow iron stores must have been approximately $10 \mathrm{~g}$. This is about half the amount usually present in the liver in idiopathic hemochromatosis $(3,5)$.

One final point is worthy of comment. In the past, the histological assessment of hemosiderin in the reticulum cells of marrow particles has been widely used as possibly the best method for assessing the status of iron stores in an individual $(7,26,33,34)$. In the present investigation, a comparison was made between histological gradings and chemical estimations of storage iron in the marrow. The good agreement obtained over a wide range of iron concentrations further confirms the validity of the histological assessment of marrow particles as a useful means of gauging the size of reticuloendothelial stores.

\section{SUMMARY}

Total bone-marrow iron stores were estimated in 61 human subjects by use of an isotopic dilution technique. The mean value in 24 white males was $288 \mathrm{mg}$ as compared with $99 \mathrm{mg}$ in 17 white females. The high incidence of iron overload in Bantu adults was reflected in the finding of a mean value of $1,629 \mathrm{mg}$ in 15 Bantu males.

Chemical analyses of iron concentrations in the marrows and livers of 199 white and Bantu necropsy subjects revealed a close correlation over a wide range of iron concentrations.

There was moderately good agreement between histological assessments of bone-marrow iron stores and chemical estimations of iron concentrations.

\section{ACKNOWLEDGMENTS}

The authors are indebted to Mr. L. Fatti, Mr. P. Marchand, Mr. D. Fuller, Mr. E. Joubert, Mr. G. Katz, and $\mathrm{Mr}$. I. Opeskin for access to patients under their care and to Professor B. J. P. Becker and Dr. C. Isaacson, who kindly supplied the necropsy material. Thanks are also due to Mr. A. D. Joffe for help with the statistical analyses.

\section{REFERENCES}

1. Granick, S. Iron metabolism in animals and plants in Trace Elements. New York, Academic Press, 1958, p. 367.

2. Granick, S. Ferritin: its properties and significance for iron metabolism. Chem. Rev. 1946, 38, 379.

3. Sheldon, J. H. Haemochromatosis. London, Oxford University Press, 1935, pp. 205, 208.

4. Gross, H., M. Sandberg, and O. M. Holly. Changes in copper and iron retention in chronic diseases accompanied by secondary anemia. II. Changes in liver, spleen and stomach. Amer. J. med. Sci. 1942, 204, 201.

5. Butt, E. M., R. E. Nusbaum, T. C. Gilmour, and S. L. Didio. Trace metal patterns in diseased states. I. Hemochromatosis and refractory anemia. Amer. J. clin. Path. 1956, 26, 225.

6. Haskins, D., A. R. Stevens, Jr., S. Finch, and C. A. Finch. Iron metabolism. Iron stores in man as measured by phlebotomy. J. clin. Invest. 1952, 31, 543.

7. Rath, C. E., and C. A. Finch. Sternal marrow hemosiderin. A method for the determination of available iron stores in man. J. Lab. clin. Med. 1948, 33, 81.

8. Bothwell, T. H., and B. A. Bradlow. Siderosis in the Bantu. A combined histopathological and chemical study. Arch. Path. 1960, 70, 279.

9. Roth, O., B. Jasiński, and H. v. Bidder. Das Gewebeeisen beim Menschen bei normalen und patho- 
logischen Zuständen. Helv. med. Acta 1951, 18, 159.

10. Mazur, A., and E. Shorr. A quantitative immunochemical study of ferritin and its relation to the hepatic vasodepressor material. J. biol. Chem. 1950, $182,607$.

11. Huff, R. L., P. J. Elmlinger, J. F. Garcia, J. M. Oda, M. C. Cockrell, and J. H. Lawrence. Ferrokinetics in normal persons and in patients having various erythropoietic disorders. J. clin. Invest. 1951, 30, 1512.

12. Huff, R. L., T. G. Hennessy, R. E. Austin, J. F. Garcia, B. M. Roberts, and J. H. Lawrence. Plasma and red cell iron turnover in normal subjects and in patients having various hematopoietic disorders. J. clin. Invest. 1950, 29, 1041.

13. Suit, H. D. A technique for estimating the bone marrow cellularity in vivo using ${ }^{50} \mathrm{Fe}$. J. clin. Path. 1957, 10, 267.

14. Donohue, D. M., B. W. Gabrio, and C. A. Finch. Quantitative measurement of hemopoietic cells of the marrow. J. clin. Invest. 1958, 37, 1564.

15. Donohue, D. M., R. H. Reiff, M. L. Hanson, Y. Betson, and C. A. Finch. Quantitative measurement of the erythrocytic and granulocytic cells of the marrow and blood. J. clin. Invest. 1958, 37, 1571.

16. Bothwell, T. H., S. Callender, B. Mallett, and L. J. Witts. The study of erythropoiesis using tracer quantities of radioactive iron. Brit. J. Haemat. 1956, 2, 1.

17. Metz, J., N. W. Levin, and D. Hart. Effect of altitude on the body/venous haematocrit ratio. Nature (Lond.) 1962, 194, 483.

18. Brückmann, G., and S. G. Zondek. Iron, copper and manganese in human organs at various ages. Biochem. J. 1939, 33, 1845.

19. McCance, R. A., E. M. Widdowson, and L. R. B. Shackleton. The nutritive value of fruits, vegetables and nuts in Medical Research Council Special Report. London, His Majesty's Stationery Office, 1936, p. 21.

20. Mazur, A., and E. Shorr. Hepatorenal factors in circulatory homeostasis. IX. The identification of the hepatic vasodepressor substance, VDM, with ferritin. J. biol. Chem. 1948, 176, 771.

21. Shoden, A., and P. Sturgeon. Hemosiderin. I. A physicochemical study. Acta haemat. (Basel) 1960, 23, 376.

22. Gillman, J., J. Mandelstam, and T. Gillman. A comparison of chemical and histological estimations of the iron and copper content of the livers of Africans in relation to the pathogenesis of cytosiderosis and cirrhosis (haemochromatosis). S. Afr. J. med. Sci. 1945, 10, 109.

23. Dry, D. S. Improved methods for the demonstration of mitochondria, glycogen, fat and iron in animal cells. S. Afr. J. Sci. 1945, 41, 298.

24. Finch, C. A. Body iron exchange in man. J. clin. Invest. 1959, 38, 392.

25. Kerr, L. M. H. A method for the determination of non-haem iron in bone marrow. Biochem. J. $1957,67,627$.

26. Stevens, A. R., Jr., D. H. Coleman, and C. A. Finch. Iron metabolism : clinical evaluation of iron stores. Ann. intern. Med. 1953, 38, 199.

27. Bothwell, T. H. Unpublished data.

28. Finch, S. C., and C. A. Finch. Idiopathic hemochromatosis, an iron storage disease. A. Iron metabolism in hemochromatosis. Medicine (Baltimore) $1955,34,381$.

29. Higginson, J., T. Gerritsen, and A. R. P. Walker. Siderosis in the Bantu of Southern Africa. Amer. J. Path. 1953, 29, 779.

30. Wainwright, J. Siderosis in the African. S. Afr. J. Lab. clin. Med. 1957, 3, 1.

31. Bothwell, T. H., and C. Isaacson. Siderosis in the Bantu. A comparison of incidence in males and females. Brit. med. J. 1962, 1, 522.

32. Walker, A. R. P., and U. B. Arvidsson. Iron "overload" in the South African Bantu. Trans. roy Soc. trop. Med. Hyg. 1953, 47, 536.

33. Davidson, W. M., and R. F. Jennison. The relationship between iron storage and anaemia. J. clin. Path. 1952, 5, 281.

34. Beutler, E., W. Drennan, and M. Block. The bone marrow and liver in iron-deficiency anemia. A histopathologic study of sections with special reference to the stainable iron content. J. Lab. clin. Med. 1954, 43, 427. 